\title{
Intergeneration Familial Risk and Psychosocial Correlates for Anxiety Syndromes in Children and Adolescents in a Developing Country
}

\author{
Jorge Javier Caraveo-Anduaga \\ Instituto Nacional de Psiquiatría "Ramón de la Fuente Muñiz" \\ México
}

\section{Introduction}

In the last decade of the 20th century a growing body of data on psychiatric disorders, from both clinical an epidemiological settings, signalled toward the childhood onset of adult psychiatric disorders (Rapoport, 2000). Epidemiological studies included in the International Consortium of Psychiatric Epidemiology (ICPE) showed that anxiety disorders tend to be chronic and relatively stable as compared to affective and substance-use disorders (Kessler et al., 2003). Furthermore, some anxiety disorders such as specific phobias and separation anxiety disorder have an early lifetime-onset. Also, studies on adult populations have shown that at least one third of all cases are comorbid and that psychiatric comorbidity is proportionally higher among persons with anxiety disorders (Caraveo et al., 1999). The study of comorbidity between different types of disorders: anxiety, affective and substanceuse showed that the onset of the former usually precedes use, abuse and dependence on alcohol and other substances (Merikangas et al., 1998). Also, the comorbidity of depressive episodes with all anxiety disorders was striking, showing that all primary anxiety disorders that were not in remission were powerful predictors of the emergence of a depressive episode. A question raised by these results was whether anxiety disorders are a causal factor for depressive episodes or simply markers of other causes (Andrade et al., 2003).

From a developmental perspective the interest in studying general psychopathology as well as specific psychiatric disorders, the sequence in which they develop, the form they take in childhood and adolescence, and how they evolve into adulthood, has important public health and preventive implications (Weissman et al., 2000; Kessler et al., 2003).

As a group, anxiety disorders are frequent and persistent in childhood and adolescence. A fair estimate of current prevalence for any anxiety disorder accompanied by impairment is between 5 and 10\% (Klein \& Pine, 2002) Separation anxiety disorder (SA), specific phobias $\mathrm{SP}$ ) and generalized anxiety disorder (GA) (previously defined as overanxious disorder in DSM-III) are the most common. Anxiety disorders are especially susceptible to impairment thresholds; however, the importance of impairment is uncertain in early diagnoses. Moreover, anxiety symptoms that are not impairing in early childhood may become so as development and life-experiences continues (Malcarne et al., 2010).

Findings from family studies, either using a "top-down" design where the children of parents with anxiety disorders are evaluated or a "bottom-up" design which ascertain the 
parents of children with anxiety disorders, have clearly establish the cross-generation transmission of anxiety from parents to children (Klein \& Pine, 2002). Kendler et al. (1995) attempted to disentangle genetic and environmental factors underlying several psychiatric adult disorders including phobias, GAD, panic disorder (PD), and major depression (MDD). They concluded from their study that:

1. The risk conferred by genes and environment for each disorder is distinctive.

2. Genetic influence on the disorders is not particularly highly specific or highly nonspecific.

3. Anxiety disorders are heterogeneous.

4. Regarding specific relationships, they find evidence for shared genetic risk factors for MDD and GAD, and for separate shared genetic risk factors for panic disorder and phobias.

Besides genetic risk factors, behavioural inhibition (a consistent tendency of children to display fear and withdrawal in unfamiliar situations) also deserves attention (Kagan et al., 1984). Results from different studies suggest that an inhibited temperament in early childhood is associated with the later development of anxiety disorders (Biederman et al., 2001; Schwartz, Snidman, \& Kagan, 1999) as well as depression (Caspi et al., 1996; Hayward et al., 1998).

Also, as findings also reveal the importance of individual-specific environmental experiences on the risk of internalizing disorders, various aspects of parents-child interactions such as modelling of avoidant behaviour through parental overprotectiveness, harsh rearing practices and failure to soothe children, have been suggested as contributing to child anxiety disorders although these effects, by definition, cannot explain familial clustering (Kovacs M. \& Devlin B, 1998).

All common psychiatric disorders where a genetic basis is suspected, corresponds to the so called "complex disorders". These are the result of the interaction between genetic liability and environmental factors. By this means, epidemiologist and genetic interests convey and there is a need for a common methodology. Intergenerational studies, have become of special interest and several prospective studies are underway (see Journal of Abnormal Child Psychology vol. 31 (2), 2003) Interest in this kind of studies is that heritable risk and biological markers (e.g., temperamental variables, elevated cortisol levels) of emotional disorder that are identifiable in early childhood may be passed across consecutive generations (e.g., Ashman el al., 2002; Goldsmith, Buss, \& Lemery, 1997). In a like manner, psychosocial characteristics that increase the risk of emotional disturbances may be passed from parent to child via processes such as modelling and direct communications (Pettit et al., 2008).

To the extent that these genetic, biological, and psychosocial characteristics - and their attendant risk-are transmitted from one generation to the next, an intergenerational mediation model (i.e., G1 G2 G3) may best characterize the development of psychopathology in general as well as for emotional disorders.

As most of the studies published are based on Caucasian populations and in developed countries, there is the need for data from studies in other countries with different ethnicity, cultural and socio-economic conditions.

For this chapter, we will present results from an epidemiological study carried out in Mexico City where familial risk for developing psychopathology across three generations (Caraveo, et al., 2005) was included as a complementary objective. 


\section{The familial risk for developing anxiety disorders across three generations in Mexico City: A general population study}

\subsection{Background}

In 1988, as part of the first National Addictions Survey, the National Mental Health Survey was applied in a sub-sample of 2025 adults aged between 18 and 65. This study was the first of its kind to attempt to estimate the prevalence of specific psychiatric disorders in Mexico (Caraveo et al., 1996). In that same study, it was decided to investigate the prevalence of probable psychiatric disorders in childhood using an instrument employed by the $\mathrm{WHO}$, the Report Questionnaire for Children (Giel et al., 1981). The results indicated that $15.6 \%$ of the child population between 3 and 12 years old had mental health problems, half of which $(7 \%)$ could be considered severe cases (Caraveo et al., 1993). Researchers also studied the association between the presence of psychopathology in children and the presence of depression and alcohol consumption in parents, highlighting the need to study and deal jointly with these problems in the population (Caraveo et al., 1994; 1995).

In 1994, with the experience and knowledge acquired and bearing in mind the experience from the National Comorbidity Survey in the United States (Kessler et al., 1994), a broadly comprehensive epidemiological project was submitted and approved to study the prevalence of specific psychiatric disorders among the general adult population in Mexico City (Caraveo et al., 1998). A version of CIDI 1.1 modified by the University of California in Fresno (CIDI-Fresno) (Vega et al., 1998) was used as the basic epidemiological clinical instrument. The translation, carried out by the Mexican Institute of Psychiatry, preserved the original official translation of CIDI 1.1., as well as the contents of all the necessary items for carrying out a diagnosis according to the International Classification of Diseases ICD-10 (WHO, 1993).

The methodological rigor with which this research project was planned and developed enabled the data obtained to be incorporated into the first generation of studies of the International Consortium in Psychiatric Epidemiology (ICPE) (Aguilar-Gaxiola, et al., 2000) which facilitated international comparison and yielded interesting, important results for the development of the discipline.

In Mexico, there are no epidemiological familial studies on the most common psychiatric disorders. The survey started the collection of data seven months after a very severe financial crisis in the country, thus, impact of ongoing psychosocial adjustments in the population are of special interest. A distinctive and original characteristic of the present study is that most epidemiological research about psychiatric disorders and mental health problems have not investigated the presence of adult psychopathology and mental health problems in their parents as well as in their children (Caraveo et al., 2005). Moreover, to our knowledge, when we started the research project there was not a family study that had examined familial risk across three generations from a large epidemiological sample. However, in the last decade several intergenerational studies have been published (Brook et al. 2003; Thornberry et al. 2003; Hammen et al., 2004; Weissman et al., 2005;Pettit et al., 2008; Warner et al., 2008) but none have focused primarily on anxiety disorders as an outcome in the offspring.

\subsection{Objective}

Our goal was to investigate the familial risk for the development of psychopathology, including anxiety syndromes, across three generations. 


\subsection{Method}

For the present study, the family-history method was used. The study was designed as a household survey on a representative sample of the adult population aged 18 - 65 years in Mexico City (Caraveo et al., 1999). Briefly, a standardized assessment for adults' lifetime prevalence of psychiatric disorders was obtained via an amended version of the Composite International Diagnostic Interview, CIDI. 1.1. The diagnostic categories included were:

Anxiety disorders: Agoraphobia, social phobia, specific phobias, generalized anxiety, panic and obsessive-compulsive disorder.

Affective disorders: Depressive episodes, dysthymia, hypomania and mania.

Disorders due to the use of psychotropic substances: distinguishing between abuse and alcohol dependence and other substances that include: sedatives, tranquilizers, stimulants, analgesics, inhalants, marijuana, cocaine, hallucinogens and heroin.

Response rate was $60.4 \%$. The total sample size was 1932 adult subjects (probands, Generation 2). In addition to the CIDI, all respondents provided information on the psychiatric history of their parents (Generation 1) about anxiety, affective and substance-use disorders following the Family-history research criteria (Andreasen et al., 1977; 1986; Kendler et al., 1997). Also, 925 respondents with children aged 4 - 16 years living at the same household were interviewed about them (1686 children and adolescents, Generation 3) using a standardized screening questionnaire for assessing psychopathology, the CBTD.

The Brief Screening and Diagnostic Questionnaire (CBTD for its initials in Spanish) is a 27item questionnaire answered by the parents of the child exploring symptoms frequently reported as motives for seeking attention at the outpatient mental health services. Presence of the symptom requires that each item has to be reported as "frequently" presented. The internal consistency of the questionnaire showed a Cronbach's alpha of 0.81 , range: 0.76 to 0.85 (Caraveo, 2006). Diagnostic algorithms in order to define probable DSM-IV disorders in children were created based on data from this epidemiological study (Caraveo, 2007).

For comparisons, adult probands' lifetime diagnoses (ICD-10) as well as psychiatric history of their parents were grouped as follows: 1. Only anxiety disorders; 2. Only affective disorders; 3. Only substance-use disorders; 4. Comorbid anxiety-affective disorders; 5. Comorbid anxiety-affective-substance use disorders; 6 . No lifetime psychiatric diagnoses.

For children, caseness was defined first, based on the questionnaire score for those at the 9th decil and beyond ( $\geq 5$ symptoms) and second, two screening anxiety syndromes were identified: generalized anxiety and anxiety with inhibition (Caraveo, 2006; 2007).

The generalized anxiety screening syndrome was defined as follows: Key symptom: a positive response to the question: Does the child gets scared or nervous for no good reason?, and at least two of the following: can't seat still, irritable, sleep problems, and frequent nightmares.

The anxiety with inhibition screening syndrome was defined as follows: Key symptom: a positive response to the question: Is the child excessively dependent or attached to adults?; and at least two positive answers on the following: aloof, frequent headaches, afraid of school, physical complains without a medical problem, sleep problems, low weight, overweight, do not work at school, and backward compared to other children.

Concurrent validity with DSM-IV anxiety diagnoses using the E-MiniKid standardized interview (Sheehan et al., 2000) showed Kappa agreement to be 0.53 and 0.68 respectively, and using Yule's Y coefficient results were 0.65 and 0.92 respectively. Receiver Operating Characteristic Curves (ROC) analyses showed Area under the Curve (AUC) to be 0.82 and 0.78 respectively (Caraveo et al., 2011 accepted). 
To estimate the familial morbid risk for children and adolescents with anxiety syndromes, interaction of familial psychopathology across generations was defined as follows:

Psychiatric history only in grandparents (G1); psychiatric history only in proband (mother or father, G2); psychiatric history on both previous generations (G1 \& G2). The research general schema for this chapter is as follows:

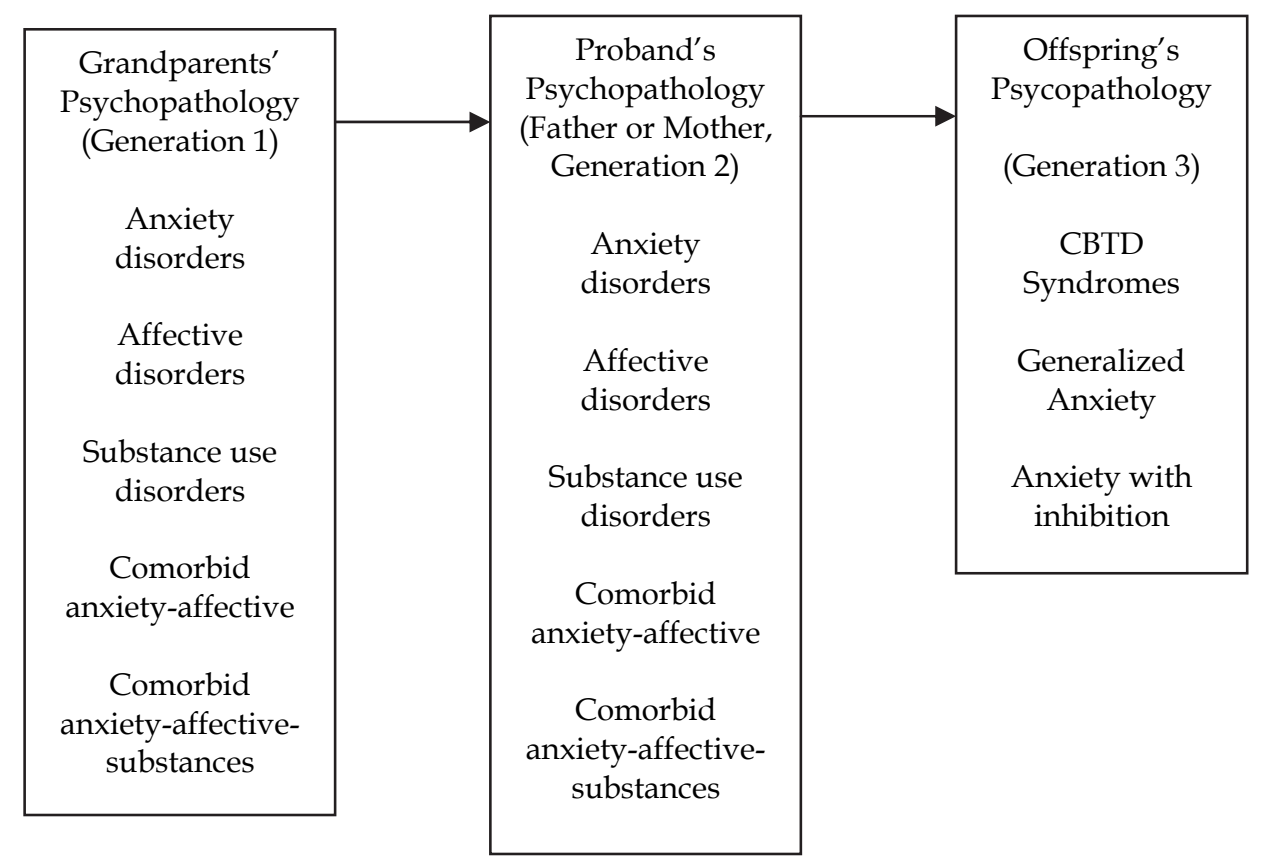

Analyses were done using the Stata 8.0 program. Variance and confidence interval estimation accounted for the complex stratified sampling of the survey, as well as for the clustering by family units that has been extensively described elsewhere (Caraveo et al., 1998, 2002; Vega et al., 2002).

Morbid risk in terms of the odds ratio was calculated using generalized estimating equations (GEE) population-averaged models with an exchangeable structure. GEE is an iterative procedure, using quasi-likelihood to estimate the regression coefficients; the relationships between the variables of the model at different time-points are analysed simultaneously. Because the repeated observations within one subject are not independent of each other, a correction must be made for these within-subject correlations choosing a correlation structure. In an exchangeable structure, as used in this study, the correlations between subsequent measurements are assumed to be the same, irrespective of the length of the time interval (Twisk, 2003).

Analyses were carried out controlling for the effect of different potential confounding variables. The first group included: grandparents' gender, proband's gender and age, children's gender and age, proband's labour status, and household income. The second group included the following proband's psycho-social variables: relationship with spouse, stress at work, couple's total work hours per week, worries between home and work, perception of family support (not living at the same household), perception of community 
support, own health's perception, and social isolation. On these, the survey included specific sections with questions and scales that were used by Dr. Kessler at the NCS and described elsewhere (Caraveo et al., 1998). Scores were converted into dummy variables using quartiles.

As a multi-nominal sampling was used, and the odds ratios are always an over-estimation of the real population's relative risk, GEE population-averaged analysis with Poisson regression was performed based on the results of the most complete previous models (McNutt et al., 2003). Also, as the data are representative of the population and a wide comprehensive approach of psycho-social variables was included, the attributable risk in the population was also obtained from the complete models with GEE population-averaged logistic analysis.

\subsection{Results}

Characteristics of the sample are shown in Table 1. Proband's mean age was 34.8 years old, $55 \%$ had one offspring, $30.5 \%$ had two, $11.3 \%$ had three, $3.2 \%$ had up to six offspring. Children mean age was 9.7 years old; distribution by age groups was as follows: $4-5$ years old $16.3 \%$, 6-8 years old $25.5 \%$, 9-12 years old $30.9 \%$, and $13-16$ years old $27.4 \%$. The estimated household income was divided into 5 levels (Caraveo et. al, 1998): $26.04 \%$ were at the bottom, $27.35 \%, 26.09 \%, 16.94 \%$ in subsequent levels, and only $3.6 \%$ at the top.

$\begin{array}{cccccc} & \text { Males } & \text { Females } & \text { Total } & \text { Cases } & \begin{array}{c}\text { Non } \\ \text { cases }\end{array} \\ \begin{array}{c}\text { Probands (Gen 2) } \\ \text { Grandparents (Gen 1) }\end{array} & 1371 & 1061 & 1932 & 552 & 1380 \\ \begin{array}{c}\text { Probands (Gen 2) with offspring } \\ \text { aged 4 to 16 years }\end{array} & 381 & 1404 & 2743 & 647 & 2096 \\ \begin{array}{c}\text { Children \& adolescents (Gen 3) } \\ \text { (6) }\end{array} & 865 & 821 & 1686 & 269 & 1416\end{array}$

Table 1. Sample Characteristics

Prevalence of psychiatric disorders by groups in G1 and G2 are shown in Table 2

$\begin{array}{ccc}\text { Psychiatric Antecedents } & \text { Grandparents } & \text { Parents } \\ & \%(95 \% \mathrm{CI}) & \%(95 \% \mathrm{CI}) \\ \text { Anxiety only } & 1.0(0.2,1.9) & 6.2(4.1,5.8) \\ \text { Depression only } & 7.4(4.9,9.9) & 5.4(3.6,7.2) \\ \text { Substances only } & 6.4(4.2,8.7) & 0.6(0.0,1.3) \\ \text { Anxiety \& depression } & 10.6(8.4,12.9) & 3.8(1.8,5.8) \\ \text { Anxiety, depression \& substances } & 11.9(9.2,14.7) & 3.5(2.2,4.9)\end{array}$

Table 2. Prevalence of psychiatric disorders on G1 and G2

Prevalence of the screening anxiety syndromes in children an adolescent is $4.1 \%$ (CI: 2.7, 5.6) and $4.0 \%$ (CI: 2.7, 5.3) for generalized anxiety and anxiety with inhibition, respectively. Both syndromes are more prevalent in boys, $5.4 \%$ and $5.0 \%$, than in girls, $2.9 \%$ and $3.1 \%$, respectively. 
2.4.1 Does familial psychopathology, that is, any type of disorder in the two previous generations is associated with the report of screening anxiety syndromes in the offspring? Results on Table 3 show that psychopathology on G1 is not significantly associated with the report of any of the two screening anxiety syndromes in G3. However, the probability for developing the generalized anxiety syndrome in the offspring is significantly associated, in terms of the odds ratio, 6-fold increase, when there is history of psychiatric disorders in the parent, Gen-2, and considerably increases to 24-fold increase when there are also psychiatric antecedents in grandparents (G2 \& G3). The screening syndrome anxiety with inhibition in the offspring is marginally associated with familial psychopathology in G1 \& G2.

$\begin{array}{ccccc}\text { Any Psychiatric Antecedents } & \begin{array}{c}\text { Generalized anxiety } \\ \text { OR }(95 \% \text { CI })\end{array} & \text { P } & \begin{array}{c}\text { Anxiety with inhibition } \\ \text { OR }(95 \% \text { CI })\end{array} & \text { P } \\ \text { G 1 } & 2.5(0.4,15.0) & .325 & 1.1(0.3,3.8) & .926 \\ \text { G 2 } & 6.0(1.0,36.1) & .049 & --- & \\ \text { G 1 \& G 2 } & 24.3(5.4,109.8) & .000 & 3.2(0.98,10.3) & .055\end{array}$

No. obs.: 739; No. gps.:419; Wald chi2=26.15;gl=3; $p=0.000 ;$ Wald chi2=5485;gl=3; $p=0.000$

Table 3. Familial psychiatric antecedents and anxiety syndromes in the offspring, crude

2.4.2 Do gender, age, household income and work status explain, in whole or in part, the association between anxiety syndromes in the offspring and familial psychopathology?

Results on Table 4 show that for generalized anxiety the strength of the association increases notably when there is psychopathology interaction between G1 and G2. The contribution of G1 seems to arise from grandmother's psychopathology, as when controlling for sex, grandfather's psychopathology is inversely associated. The rest of the variables, not included on the Tables, did not show a statistical significant association.

For the anxiety with inhibition screening syndrome, interestingly, mother's psychopathology emerged showing a 7-fold increase, which is similar in magnitude to the G2 association with the generalized anxiety syndrome. Also, psychopathology interaction between G1 and G2 became significantly associated on the anxiety with inhibition syndrome, as well as low household income.

$\begin{array}{ccccc}\text { Any Psychiatric Antecedents } & \begin{array}{c}\text { Generalized anxiety } \\ \text { OR }(95 \% \mathrm{CI})\end{array} & \mathrm{P} & \begin{array}{c}\text { Anxiety with inhibition } \\ \text { OR }(95 \% \mathrm{CI})\end{array} & \mathrm{P} \\ \text { G1 } & 4.4(0.6,29.0) & .128 & 1.4(0.3,6.0) & .638 \\ \text { G 2 } & 6.8(1.1,40.3) & .034 & --- & \\ \text { G 1 \& G 2 } & 41.9(8.4,208.3) & .000 & 4.9(1.3,18.2) & .016 \\ \text { Grandfather } & 0.1(0.01,0.84) & .033 & \text { NS } & \\ \text { Mother } & \text { NS } & & 7.5(1.7,32.8) & .007 \\ \text { Household income } & & & 0.6(0.4,0.9) & .008\end{array}$

No. obs.: 728; No. gps.:413; Wald chi2=51.80; gl=10; $p=0.000$; Wald chi2=5411; gl=10; $p=0.000$

Table 4. Familial psychiatric antecedents and anxiety syndromes in the offspring, $1^{\text {st }}$. adjustment 
2.4.3 The final model incorporated the group of proband's psychosocial variables. On Table 5 , results show that for general anxiety the odds ratio for $G 2$ increases considerably, from almost a 7-fold increase in the previous model to a 20-fold increase, although it is important to note that the confidence interval is very wide. A little increase in the odds ratio is also observed for the association with psychopathology on both previous generations. Stress at work emerged as an important proband's psychosocial variable associated with the generalized anxiety syndrome in the offspring, while more total working hours per week is associated with the syndrome anxiety with inhibition. Having worries between home and work is inversely associated with the presence of both anxiety syndromes, while for anxiety with inhibition, relationship with spouse is also inversely associated.

$\begin{array}{lcccc} & \begin{array}{c}\text { Generalized anxiety } \\ \text { OR }(95 \% \mathrm{CI})\end{array} & \mathrm{P} & \begin{array}{c}\text { Anxiety with inhibition } \\ \text { OR }(95 \% \mathrm{CI})\end{array} & \mathrm{P} \\ \text { G 1 } & 5.6(0.5,56.8) & .113 & 1.1(0.2,4.8) & .937 \\ \text { G 2 } & 20.4(1.5,282.7) & .023 & 7.7(1.04,56.5)^{*} & .046 \\ \text { \& G 2 } & 47.0(5.5,405.0) & .000 & 2.2(0.6,7.5) & .208 \\ \text { s at work } & 6.5(1.9,22.0) & .003 & -- & \\ \text { en home and work } & 0.24(0.07,0.8) & .020 & 0.21(0.06,0.76) & .017 \\ & -- & & 1.8(1.04,3.0) & .034 \\ \text { ours per week } & -- & & 0.45(0.26,0.79) & .006\end{array}$

No. obs.: 698; No. gps.:396; Wald chi2=47.67; gl=17; $p=0.000$; Wald chi2=4197; gl=17; $p=0.000$

*only mother's psychiatric antecedents

Table 5. Familial psychiatric antecedents and anxiety syndromes in the offspring, 2nd. Adjustment

As the odds ratios are always an over-estimation of the real relative risk, GEE populationaveraged analysis with Poisson regression was performed to obtain the prevalence risk ratios, PRR. Results on Table 6 show that PRR are smaller than previous adjusted odds ratios. Also, for anxiety with inhibition, besides the variable working more hours per week, being employed and living in a low income household, completed the risk picture. Considering all the variables studied in the population, familial psychopathology interaction between G1 \& G2 explains most of the risk for the generalized anxiety syndrome in the offspring, along with higher stress at work on G2. In contrast, for the anxiety with inhibition syndrome, psychiatric familial atributable risk is low, but most important is that a better couple's relationship is a considerable protective factor.

2.4.4 What specific groups of psychiatric familial disorders are associated with the development of anxiety syndromes in the offspring?

In order to answer this question, groups of psychiatric disorders in G1 and G2 were entered in the analyses as independent covariates. Because of the extremely low prevalence of $G 3$ anxiety syndromes in the non-comorbid grandparents' antecedents groups, the analysis was restricted to the comorbid-anxiety groups. Results on Table 7 shows that comorbid anxiety either with depression or with it and substance abuse in grandparents are significantly associated with the generalized anxiety syndrome in G3, but not with the screening syndrome anxiety with inhibition. All groups of parent's psychiatric disorders are 
associated with generalized anxiety, and odds ratios are quite consistent for all groups, except for the depression-only group. For anxiety with inhibition, parent's comorbid anxiety-depression as well as anxiety-only, show significant association.

\begin{tabular}{|c|c|c|c|c|}
\hline & $\begin{array}{c}\text { Generalized } \\
\text { PRR (95\% CI) }\end{array}$ & $\begin{array}{c}\text { Anxiety } \\
\text { Attributable risk \% }\end{array}$ & $\begin{array}{l}\text { Anxiety with } \\
\text { PRR (95\% CI) }\end{array}$ & $\begin{array}{c}\text { Inhibition } \\
\text { Attributable risk \% }\end{array}$ \\
\hline G 1 & $5.5(0.6,52.4)$ & 1.2 & $1.0(0.2,4.3)$ & 0.5 \\
\hline G 2 & $17.8(1.5,213.7)_{1}$ & 3.5 & $6.8(1.1,41.6)^{*} 1$ & $2.2^{*}$ \\
\hline G $1 \& G 2$ & $35.0(4.7,259.3) 2$ & 10.6 & $2.0(0.6,6.0)$ & 3 \\
\hline $\begin{array}{l}\text { Stress at } \\
\text { work }\end{array}$ & $5.2(1.8,14.7) 3$ & $1,2-31.9$ & -- & \\
\hline $\begin{array}{l}\text { Household } \\
\text { income }\end{array}$ & NS & & $0.5(0.3,0.99) 1$ & $0.3-2.5$ \\
\hline Employed & & & $9.8(1.01,95.4) 1$ & 1.2 \\
\hline $\begin{array}{c}\text { Worries } \\
\text { between } \\
\text { home and } \\
\text { work }\end{array}$ & $0.26(0.09,0.8) 1$ & $1-1.6$ & $0.21(0.06,0.76) 1$ & $0.6-2.4$ \\
\hline $\begin{array}{c}\text { Working- } \\
\text { hours per } \\
\text { week }\end{array}$ & NS & & $1.7(1.07,2.7) 1$ & $0.1-0.9$ \\
\hline $\begin{array}{l}\text { Relationship } \\
\text { with spouse }\end{array}$ & NS & & $0.47(0.28,0.79)_{3}^{3}$ & $0.2-4.1$ \\
\hline
\end{tabular}

No. obs.: 698; No. gps.:396; Wald chi2=58.98; gl=17; $\mathrm{p}=0.000 ;$ Wald chi2=4865; gl=17; $\mathrm{p}=0.000$ *only mother's psychiatric antecedents; 1 p $<0.05 ; 2 \mathrm{p}<0.001 ; 3 \mathrm{p}<0.005$

Table 6. Familial antecedents and anxiety syndromes in the offspring, Adjusted Risk Ratios

$\begin{array}{ccccc}\text { Antecedents } & \begin{array}{c}\text { Generalized anxiety } \\ \text { OR }(95 \% \mathrm{CI})\end{array} & \mathrm{P} & \begin{array}{c}\text { Anxiety with inhibition } \\ \text { OR }(95 \% \mathrm{CI})\end{array} & \mathrm{P} \\ \text { in grandparents } & 7.1(2.8,17.9) & .000 & 1.8(0.8,4.2) & .162 \\ \text { Anxiety \& depression } & 8.2(3.3,20.7) & .000 & 1.7(0.7,4.3) & .262 \\ \text { Anxiety, depression \& substances } & & & & \\ \text { Antecedents } & & & & .019 \\ \text { in parents } & 5.7(2.1,15.9) & .001 & 3.3(1.2,8.8) & .532 \\ \text { Anxiety- only } & 3.5(1.2,10.1) & .022 & 1.6(0.4,7.1) & .000 \\ \text { Depression - only } & 5.7(2.3,14.1) & .000 & 7.7(2.8,21.0) & \\ \text { Anxiety \& depression } & 5.5(1.1,27.0) & .038 & -- & \end{array}$

No. obs.: 1100; No. gps.:608; Wald chi2=59.05; gl=6; p= 0.000; Wald chi2=22.62; gl=5; $p=0.000$

Table 7. Specific familial antecedents and anxiety syndromes in offspring, crude.

2.4.5 Does the magnitude of the association remains or is it modified when adjustment for the first block of covariables is introduced to the model? Do gender, age, household income and labour status play a role for the development of anxiety syndromes in the offspring? 
The odds ratios between grandparents' history of anxiety-comorbid disorders and the presence of both anxiety syndromes in their grandchildren as shown in Table 8 are practically the same as in the previous model. That is, history of anxiety-comorbid disorders on G1 is significantly associated with general anxiety screening syndrome on G3, but not with the screening syndrome anxiety with inhibition.

Although none of the first group of potential confounding variables was found significantly associated with anxiety syndromes on G 3 , some effects on the magnitude of the association between groups of psychiatric disorders on G 2 and the screening anxiety syndromes on G 3 became evident. The strength of the association between anxiety-only, depression-only and comorbid anxiety-depression disorders with the generalized anxiety syndrome in the offspring increases, while an antecedent of comorbid anxiety-depression and substance abuse is no longer significant. For the anxiety with inhibition screening syndrome, only history of comorbid anxiety-depression remains significantly associated.

$\begin{array}{ccccc}\text { Antecedents } & \begin{array}{c}\text { Generalized anxiety } \\ \text { OR }(95 \% \mathrm{CI})\end{array} & \mathrm{P} & \begin{array}{c}\text { Anxiety with inhibition } \\ \text { OR }(95 \% \mathrm{CI})\end{array} & \mathrm{P} \\ \text { in grandparents } & 7.3(2.9,18.4) & .000 & 1.9(0.8,4.4) & .134 \\ \text { Anxiety \& depression } & 8.6(3.4,21.4) & .000 & 1.7(0.7,4.3) & .238 \\ \text { Anxiety, depression } & & & & \\ \quad \text { \& substances } & & & & .092 \\ \quad \text { Antecedents } & & & 2.3(0.9,6.5) & .857 \\ \quad \text { in parents } & 6.6(2.2,19.8) & .001 & 1.1(0.2,5.2) & .002 \\ \text { Anxiety- only } & 4.0(1.3,12.7) & .018 & 5.3(1.9,15.2) & \\ \text { Depression - only } & 7.1(2.5,20.6) & .000 & -- & \\ \text { Anxiety \& depression } & 4.4(0.7,26.7) & .105 & & \end{array}$

No. obs.:1083; No. gps.:599; Wald chi2=74.21;gl=12; $p=0.000 ;$ Wald chi2=30.63; gl=11; $p=0.001$

Table 8. Specific familial antecedents and anxiety syndromes in offspring, first adjustment.

2.4.6 When adjustment for the proband's psychosocial variables is introduced in the analysis, results on Table 9 show that female children and adolescents develop less generalized anxiety syndrome than males. Also, as previous results have shown in Table 5, the relationship with spouse is inversely associated with the presence of anxiety with inhibition in the offspring. The strength of the association between comorbid anxiety on G 1 and both anxiety syndromes on G3 remain more or less the same. However, changes emerged between G2 and G3: Anxiety-only, became associated with the syndrome anxiety with inhibition; depression-only is marginally associated with generalized anxiety.

GEE population-averaged analysis with Poisson regression was performed to obtain the PRR. Results on Table 10 show that depression-only reaches statistical significance, as it was only marginally associated in the precedent analysis with generalized anxiety in the offspring. However, PRR is almost half compared to parent's antecedents of anxiety-only disorders.

Attributable risk in the population relies on familial antecedents of anxiety, either alone or comorbid, mainly, with depression.

Anxiety with inhibition in the offspring show only marginal significant PRR with antecedents of anxiety-only in parents, and no other type of psychiatric history has a significative associated risk with this anxiety screening syndrome. However, its worth to 
note that attributable risk in the population follows the same path as for generalized anxiety, although roughly at half the risk.

$\begin{array}{ccccc}\text { Antecedents } & \begin{array}{c}\text { Generalized anxiety } \\ \text { OR }(95 \% \mathrm{CI})\end{array} & \mathrm{P} & \begin{array}{c}\text { Anxiety with inhibition } \\ \text { OR }(95 \% \mathrm{CI})\end{array} & \mathrm{P} \\ \text { in grandparents } & 8.1(2.9,22.4) 1 & .000 & 2.2(0.9,5.1) & .070 \\ \text { Anxiety \& depression } & 7.1(2.5,19.9) 1 & .000 & 1.4(0.4,5.2) & .630 \\ \text { Anxiety, depression \& substances } & & & & \\ \text { Antecedents } & & & & .050 \\ \text { in parents } & 7.4(2.4,22.9) 1 & .001 & 2.7(1.0,7.1) 3 & .705 \\ \text { Anxiety- only } & 3.3(0.99,10.9) & .051 & 1.3(0.3,6.4) & .110 \\ \text { Depression - only } & 6.1(1.8,20.5) 1 & .004 & 2.6(0.8,8.5) & \\ \text { Anxiety \& depression } & 1.5(0.1,18.4) & .733 & -- & .010 \\ \text { Anxiety, depression \& substances } & 0.4(0.2,0.98) 3 & .044 & \mathrm{NS} & \\ \text { Daughter } & \mathrm{NS} & & 0.6(0.4,0.9) 4 & 4 \\ \text { Relationship with spouse } & & & \end{array}$

No. obs.:1025; No. gps.:567; Wald chi2=99.04; gl=20; p= 0.000; Wald chi2=42.49; gl=19; p= 0.001

Table 9. Specific familial antecedents and anxiety syndromes in offspring, second adjustment

\begin{tabular}{|c|c|c|c|c|}
\hline $\begin{array}{c}\text { Antecedents } \\
\text { in grandparents }\end{array}$ & $\begin{array}{c}\text { Generalized } \\
\text { PRR (95\% CI) }\end{array}$ & $\begin{array}{c}\text { Anxiety } \\
\text { Attributable Risk \% }\end{array}$ & $\begin{array}{l}\text { Anxiety with } \\
\text { PRR (95\% CI) }\end{array}$ & $\begin{array}{c}\text { Inhibition } \\
\text { Attributable Risk \% }\end{array}$ \\
\hline $\begin{array}{l}\text { Anxiety \& } \\
\text { depression }\end{array}$ & $7.0(2.7,18.1)$ & 6,7 & $2.0(0.9,4.5)$ & 3.5 \\
\hline $\begin{array}{c}\text { Anxiety, } \\
\text { depression \& } \\
\text { substances }\end{array}$ & $6.2(2.4,15.8)$ & 8.8 & $1.4(0.4,4.8)$ & 1.5 \\
\hline $\begin{array}{l}\text { Antecedents } \\
\text { in parents }\end{array}$ & & & & \\
\hline Anxiety- only & $5.8(2.1,15.8)$ & 10.2 & $2.4(0.98,6.0)$ * & 5.4 \\
\hline $\begin{array}{l}\text { Depression - } \\
\text { only }\end{array}$ & $3.0(1.04,8.8)$ & 3.3 & $1.3(0.3,5.8)$ & 1.4 \\
\hline $\begin{array}{l}\text { Anxiety \& } \\
\text { depression }\end{array}$ & $4.7(1.6,13.6)$ & 15.4 & $2.4(0.8,6.9)$ & 7.7 \\
\hline $\begin{array}{c}\text { Anxiety, } \\
\text { depression \& } \\
\text { substances }\end{array}$ & $1.5(0.1,18.4)$ & 1.1 & -- & \\
\hline Daughter & $0.5(0.2,0.97)$ & 1.6 & NS & \\
\hline $\begin{array}{l}\text { Relationship } \\
\text { with spouse }\end{array}$ & NS & & $0.6(0.4,0.9)$ & $0.3-4.3$ \\
\hline
\end{tabular}

No. obs.:1025; No.gps.:567; Wald chi2=123.3; gl=20; $\mathrm{p}=0.000$; Wald chi2=50.01; gl=19; $\mathrm{p}=0.000$ $1 \mathrm{p} \leq 0.001 ; 2 \mathrm{p}<0.005 ; 3 \mathrm{p}<0.05 ; 4 \mathrm{p}=0.01 ;{ }^{*} \mathrm{p}=0.54$

Table 10. Specific familial antecedents and anxiety syndromes in offspring, adjusted risk ratios 
2.4.7 Psychosocial variables are closer to actual and on-going circumstances. As in the method used for the analysis of the data the correlations between subsequent measurements have been assumed to be the same, and this does not hold for psychosocial variables, the final analysis included only information between probands $(G 2)$ and their children (G 3).

Results presented on Table 11 show that parent's history of anxiety-only as well as comorbid anxiety-depression are significantly associated with both screening anxiety syndromes in their offspring. Also, as in the previous model, male children develop more generalized anxiety as compared to females, and the relationship with spouse is inversely associated with the presence of anxiety with inhibition in the descendant. Interestingly, two variables, one from each adjustment's group, became associated with anxiety syndromes in the offspring: household income and proband's own health perception. The first, only associated with the generalized anxiety syndrome, while the second with both.

For generalized anxiety in the offspring, it is worth noting that the strength of the association with parents' anxiety-only disorders diminishes more than a half as compared when grandparents antecedents were included in the previous analysis, while comorbid anxiety-depression antecedents shows a slight increase in the odds ratio, and depressiononly diminishes one-fold.

Comparatively, for the anxiety with inhibition syndrome in the offspring the strength of the association with parents' comorbid anxiety-depression increases one-fold and becomes significantly associated, while anxiety-only and depression-only show a very slight increase.

$\begin{array}{ccccc}\text { Antecedents } & \text { Generalized anxiety } & \text { P } & \text { Anxiety with inhibition } & \mathrm{P} \\ \text { in parents } & \text { OR }(95 \% \mathrm{CI}) & & \text { OR }(95 \% \mathrm{CI}) & \\ \text { Anxiety- only } & 3.5(1.6,7.9) & .002 & 3.0(1.3,6.8) & .012 \\ \text { Depression- only } & 2.0(0.6,6.0) & .234 & 2.2(0.8,5.7) & .108 \\ \text { Anxiety \& depression } & 6.7(3.0,14.7) & .000 & 3.7(1.6,9.0) & .003 \\ \text { Anxiety, } & & & & \\ \text { depression \& } & 2.1(0.6,7.6) & .251 & -- & \\ \text { substances } & & & & \\ \text { Daughter } & 0.5(0.3,0.9) & .015 & \mathrm{NS} & \\ \text { Household income } & 1.3(1.04,1.7) & .022 & \mathrm{NS} & \\ \text { Health perception } & 1.3(1.04,1.8) & .026 & 1.4(1.1,1.8) & .005 \\ \text { Relationship with spouse } & \mathrm{NS} & & 0.7(0.5,0.9) & .021\end{array}$

No. obs.:1550; No. gps.:849; Wald chi2=67.16; gl=18; $\mathrm{p}=0.000$; Wald chi2=62.93; gl=18; $\mathrm{p}=0.000$

Table 11. Parent's disorders, psychosocial variables and anxiety syndromes in offspring

Adjusted PRR obtained with GEE population-averaged analysis with Poisson regression show only a noticeable adjustment for the risk between parent's comorbid anxietydepression and generalized anxiety in the offspring (Table 12). However, for the anxiety with inhibition syndrome, parent's antecedents of anxiety-only and comorbid anxiety disorders show a significant risk. Noteworthy, is that risk between each screening anxiety syndrome in the offspring and parent's antecedents of depression-only, is not significant. 


\begin{tabular}{|c|c|c|c|c|}
\hline $\begin{array}{l}\text { Antecedents } \\
\text { in parents }\end{array}$ & $\begin{array}{l}\text { Generalized } \\
\text { PRR (95\% CI) }\end{array}$ & $\begin{array}{c}\text { Anxiety } \\
\text { Attributable risk \% }\end{array}$ & $\begin{array}{l}\text { Anxiety with } \\
\text { PRR (95\% CI) }\end{array}$ & $\begin{array}{c}\text { Inhibition } \\
\text { Attributable risk \% }\end{array}$ \\
\hline $\begin{array}{l}\text { Anxiety- } \\
\text { only }\end{array}$ & $3.2(1.6,6.5) 2$ & 7 & $2.7(1.3,5.9) 4$ & 5.8 \\
\hline $\begin{array}{l}\text { Depression- } \\
\text { only }\end{array}$ & $1.9(0.7,5.3)$ & 1.9 & $2.1(0.9,5.1)$ & 3.4 \\
\hline $\begin{array}{l}\text { Anxiety \& } \\
\text { depression }\end{array}$ & $5.1(2.6,9.7) 2$ & 16.6 & $3.3(1.5,7.1) 1$ & 10.5 \\
\hline $\begin{array}{c}\text { Anxiety, } \\
\text { depression \& } \\
\text { substances }\end{array}$ & $2.1(0.6,6.6)$ & 1.6 & $2.9(1.1,7.8)_{3}$ & 3.4 \\
\hline Daughter & $0.51(0.3,0.9)_{3}$ & 2 & NS & \\
\hline $\begin{array}{l}\text { Household } \\
\text { income }\end{array}$ & $1.3(1.03,1.6) 3$ & $1.4-4.9$ & NS & \\
\hline $\begin{array}{l}\text { Health } \\
\text { perception }\end{array}$ & $1.3(1.02,1.7)_{3}$ & $1.1-4.6$ & $1.4(1.1,1.7) 4$ & $1.2-4.8$ \\
\hline $\begin{array}{l}\text { Relationship } \\
\text { with spouse }\end{array}$ & NS & & $0.7(0.6,0.96) 3$ & $0.4-4.1$ \\
\hline
\end{tabular}

Table 12. Parent's disorders, and anxiety syndromes in offspring, adjusted risk ratios

\section{Discussion}

This epidemiological study in the general population of Mexico City has shown evidence, consistent with results from studies on Caucasian populations in developed countries (Klein \& Pine, 2002), that familial risk for developing anxiety disorders is a fact, thus not limited by ethnicity or culture, but mediated by socio-economic conditions. Our contribution is that to our knowledge, there are no other studies that have analyzed familial risk for anxiety disorders in children and adolescents across three generations in the general population. However, some considerations and limitations of the study should be kept in mind before discussing the results.

Assessments of psychiatric history in grandparents, G1, and lifetime psychiatric diagnoses on probands, G 2, were made with accepted international criteria and epidemiological instruments (Kendler et al., 1997; Kessler et al., 2002). Screening for caseness in children and adolescents, G 3, was made with a new questionnaire: The Brief Screening and Diagnostic Questionnaire (CBTD for its initials in Spanish). It is important to highlight that the CBTD includes symptoms that are frequently reported as motives for consultation at outpatient mental health services. So, the instrument does not merely translate diagnostic criteria into questions but rather use the way that the population perceives and express concern about their children's behaviour, in order first, to define caseness and second, to identify probable disorders.

Screening syndromes for several children's psychiatric disorders were obtained from this general population study (Caraveo, 2006; 2007). The hypothesis was that data would be able to identify a generalized anxiety syndrome as well as a separation anxiety syndrome. The first was fully accomplished but not the second one. Instead of it, what has been presented as the anxiety with inhibition syndrome, emerged from the cluster analysis and do not 
resemble any accepted diagnostic category. Nonetheless, concurrent validity with DSM-IV anxiety diagnoses has been found to be good (Caraveo et al., 2011 accepted for publication). As the principal objective of the survey was focused on adult population, only one adult was selected at each household, and so familial risk across generations, is lacking on information about one parent. However, as the sample was representative of the adult population aged 18 to 64 years; morbid risk was calculated using GEE averagedpopulation models, in which the interest is the population and not the individual's risk (Twisk, 2003).

Other limitations are: This was a cross-sectional study. All information was obtained from only one person and retrospectively. Comorbidity between anxiety and other syndromes in children and adolescents were not considered for control during the analyses, and impairment associated with the screening anxiety syndromes was not assessed.

\subsection{Do the results show sufficient evidence supporting the hypothesis of a familial risk between the screening anxiety syndromes in children and adolescents and familial antecedents of psychopathology in the two precedent generations?}

From the more general standpoint, that is the association between the two screening anxiety syndromes in the offspring, G3, and any familial psychiatric history on G1, G2, and the interaction between G1 and G2, results suggest that for the generalized anxiety syndrome familial risk is more plausible than for the anxiety with inhibition syndrome.

Crude odds ratios showed that generalized anxiety is 6 times more frequent in G3 when there is history of any psychiatric disorders in the proband, G2, with a statistical significance of $\mathrm{P}<.05$, and considerably increases up to 24 times more, $\mathrm{P}<.001$, when there is also history of psychiatric disorders in grandparents, G1 and G2. Controlling the effects of potential confounding variables increased the odds ratios as well as confidence intervals indicating high variability, altough and very important, statistical significance of these morbid risks, $\mathrm{P}<.05$ and $\mathrm{P}<.001$ respectively, persisted throughout all the analyses.

Adjusting for the first block of confounders suggested that the interaction between G2 and G1 relies more on grandmothers' psychopathology. However, its statistical significance was lost when control for other variables was included. Nonetheless, its relevance should be kept in mind for further studies as the mother's figure is very important in familial relationships. An intergenerational study (Hammen et al., 2004) have presented very interesting data on how major depressive disorder (MDD) in grandmothers have an effect on grandchildren by maternal, G2, chronic interpersonal stress. On this, there is the fact that grandmothers help their descendants in nurturing and raising grandchildren especially if both parents have to work, or when their offspring are single parents.

Most important, and certainly a distinctive contribution from this study, is the documentation of the enormous increase in the association between psychopathology in G 2 and generalized anxiety in G 3 when controlling for the proband's psychosocial variables. Odds ratio raised from a 7-fold increased risk to a 20-fold increased risk between any parent's psychiatric disorder and generalized anxiety in their offspring, along with the variable stress at work with a 6-fold increased risk, $\mathrm{P}<.005$, thus indicating the impact of the financial crisis on the mental health status and well-being of the population. Moreover, the attributable risk of the variable stress at work showed a range, according to quartiles, from $1.2 \%$ to a high $31.9 \%$. To have an idea of how important the financial crisis was, here are some data: Money exchange rate increased from 3.49 pesos $x$ dollar to 9.42; devaluation represented $173.82 \%$; inflation $225.32 \%$, and acquisitive power diminished 34.79 \%(Fernández-Torres, 2005). 
Adjusted prevalence risk ratios clearly shows that morbid risk for the generalized anxiety syndrome in descendants is almost the double when there is interaction between history of psychiatric disorders on G1 and G2 as compared to only having psychiatric antecedents on G2. These first results follow the path reported on major depressive disorder, MDD, across three generations by Weissman et al. (2005) that found a 5.4-fold increased risk for any disorder in the offspring when interaction between grandparental MDD and parental MDD was present. Also, Pettit et al. (2008) using linear regression procedures reported that the interaction of G1 MDD x G2 MDD significantly predicted Anxious/Depressed scores on the Children Behavior Check List (CBCL).

Compared to the generalized anxiety syndrome, associations of the anxiety with inhibition sydrome as related to any familial psychiatric antecedents across generations and potential confounding variables, results suggest a more situational determined condition rather than a disorder with a clear familial risk. However, when adjustment was made for the first block of potential confounding variables, gender, age, household income and labour status, the interaction between history of any psychiatric disorders on G1 and G2 showed an almost 5fold increased risk, $\mathrm{P}<.02$, suggesting somekind of psychiatric familial liability and mostly on women probands. Only the lifetime history of psychiatric disorder in mothers was associated with the outcome in the offspring, when adjustment was made for the probands' psychosocial variables. In terms of the prevalence risk ratio, having -predominantly- a mother with a psychiatric disorder, employed, working as a couple more hours per week, and living in a low-income household, are risk factors associated with the outcome syndrome anxiety with inhibition in children and adolescents.

Based on these results, it is fair to ask: Is the anxiety with inhibition syndrome in descendants a gender-related parent disorder? Is it the result of different disadvantages, both individual and social?

\subsection{Do the results on the screening anxiety syndromes in children and adolescents show sufficient evidence supporting an anxiety familial risk across generations?}

With the preceding broad and encouraging panorama, the next inquire was on what kind of specific psychiatric familial antecedents are associated with the outcome of anxiety syndromes in children and adolescents. Results have shown that comorbid anxiety disorders in grandparents seems to interact with anxiety-only as well as with anxiety comorbid disorders in parents, determining a robust morbid risk for the generalized anxiety screening syndrome in descendants. Moreover, comorbid anxiety-depression followed by anxiety-only lifetime disorders in parents showed the highest attributable risk for this syndrome in the offspring, $15.4 \%$ and $10.2 \%$, respectively. In contrast, the attributable risk of parents' depression-only for this syndrome is considerably low, from $1.9 \%$ to $3.3 \%$.

These results are consistent with findings from a cohort longitudinal study over 32 years (Moffit et al. 2007) in which non-comorbid MDD involved lower levels of risk than comorbid MDD + Generalized Anxiety disorder (GAD).

Hale et al. (2009) in a prospective 5-year study in two cohorts of early and middle adolescents from the general population at The Netherlands, used a framework of structural equation modeling to investigate whether anxiety and depression disorder symptoms corresponds to one general factor or do they are two distinct disorders with parallel growth processes. The latter, was the best model and results also suggested that the development of one disorder may be affected by the initial symptom severity of the other disorder. 
Weissman et al., (2005) found a 5-fold increased risk for an anxiety disorder in grandchildren when interaction between grandparental MDD and parental MDD was present. Our results are very similar, the PRR showed a 4.7-fold increase on parents with comorbid anxiety-depression having grandparents' psychiatric antecedents as separate covariables and a 5.1-fold increase when only parents' disorders were analyzed.

Considering exclusively the risk between parents' anxiety-only disorders and the generalized anxiety syndrome in descendants, our results have shown a 5.8-fold increased risk when grandparents' psychiatric antecedents were covariates and a 3.2-fold increased risk without them. Both results are higher than the relative risk reported on G1 MDD x G2 MDD interaction and offspring MDD, 2.08-fold increase, as well as for any mood disorder, 2.42 -fold increase. As our results come from a general population sample rather than from a clinical setting, findings could suggest that familial risk for generalized anxiety across three generations is higher than the observed for MDD. However, this could be a mediation effect of the financial crisis.

On this, besides gender and familial antecedents as risk factors, offspring living in households with relative better income, and with parents reporting poor own's health perception were at increased risk for presenting generalized anxiety syndrome. The first variable indicates the struggle of mostly the middle class population, in order to face the economic crisis, while the second one also speaks about the concern on social support, a risk that is equally shared by parents with offspring showing anxiety with inhibition.

The presence of lifetime anxiety disorders in both grandparents and parents, as opposed to only one generation, may reflect higher genetic loadings for emotional disorders as observed for the generalized anxiety syndrome. In contrast, at a first glance, the anxiety with inhibition syndrome seemed not show the same pattern. However, following closely the results, in the first analysis, crude odds ratios showed that parent's comorbid anxietydepression as well as anxiety-only, are significantly associated with the outcome. Adjusting for the first group of potential confounders, only history of comorbid anxiety-depression in parents' remains significantly associated, which indicates the more severe form of the disorder as discussed earlier. However, when psychosocial variables were introduced to the model, parents' history of anxiety-only became the single psychiatric antecedent significantly associated with this syndrome. Nonetheless, odds ratios and risk ratios indicated that the morbid risk is practically the same for parents' history of anxiety-only and for comorbid anxiety-depression (Tables 9 \& 10). Moreover, the attributable risk is $5.4 \%$ for the first, while slightly higher, $7.7 \%$, for comorbid anxiety-depression, and its noteworthy the $3.5 \%$ contribution from grandparents' comorbid anxiety-depression disorders. These results suggest that the anxiety with inhibition syndrome also has a familial anxiety risk across generations, although less pronounced as compared to the generalized anxiety syndrome.

\section{Conclusion}

The present study has shown consistent evidence that anxiety syndromes in children and adolescents from the general population, as screened with the CBTD, have a clear anxietyrelated familial risk across generations. The morbid risk is more evident for the generalized anxiety syndrome, and possibly higher than what has been reported on MDD-only by other studies. However, this could be a mediation effect of the financial crisis that occurred at the time of the study. The morbid risk associated with comorbid anxiety-depression in 
precedent generations is higher than the obtained on anxiety-only disorders and almost the same as reported in multigeneration MDD studies.

The anxiety with inhibition syndrome has a less pronounced anxiety-related familial risk across generations and results suggest that it is a gender-related parent disorder where different disadvantages, both individual and social, may play a moderating role.

Findings have clinical implications; some of them have been already taken into practice. The Brief Screening and Diagnostic Questionnaire, CBTD, has been tested in primary care settings an incorporated as a basic tool for health services in Mexico City. Obtaining a screening family history of anxiety, depression and substance-abuse disorders as used in this study, as well as the assessment of impairment in children, evaluation of child-rearing practices, family style for solving problems at home, and report of domestic violence, have been tested as basic issues for the surveillance of mental health in childhood and andolescence.

\section{Acknowledgment}

This study was funded by The National Council of Science and Thechnology (CONACYT), award 2077-H9302.

\section{References}

Aguilar-Gaxiola, S., Alegría, M., Andrade, L., Bijl, R., Caraveo-Anduaga, J., Dewit, D.J., Kolody, B., Kessler, R.C., Ustun, T.B., Vega, W.A. \& Wittchen H-U. (2000) The international consortium in psychiatric epidemiology. In: Sociální psychiatrie $v$ case zmen (Social Psychiatry in Changing Times) pp. 86-96, Psychiatrické centrum; ISBN 80-85121-08-5, Praha

American Psychiatric Association. (1994) Diagnostic and statistical manual of mental disorders, (fourth edition), American Psychiatric Association, ISBN 0-89042-062-9, Washington D.C.

Andrade, L., Caraveo, A.J., Berglund, P., Bijl, R., De Graaf, R., Vollebergh, W. Dragomirecka, E., Kohn, R., Keller, M., Kessler, R.C., Kawakami, N., Orford, D., Ustun, T.B., \& Wittchen, H.U. (2003) The epidemiology of major depressive episodes: results from the International Consortium of Psychiatric Epidemiology (ICPE) surveys. International. Journal of Methods in Psychiatric Research, 12, 1, pp.3-21, ISSN 1049-8931

Andreasen, N.C., Endicott, J., Spitzer, R. L. \& Winokur, G. (1977) The family history method using diagnostic criteria. Archives of General Psychiatry, 34, pp. 1229-1235, ISSN 0003-990X.

Andreasen, N. C., Rice, J. Endicott, J., Reich, T., \& Coryell W. (1986) The Family history approach to diagnosis: How useful is it? Archives of General Psychiatry, 43, pp. 421429, ISSN 0003-990X

Ashman, S. B. Dawson, G., Panagiotides, H., Yamada, E., \& Wilkinson C. W. (2002) Stress hormone levels of children of depressed mothers. Development and Psychopathology; 14, pp. 333-349, ISSN 0954-5794.

Biederman, J., Hirshfeld-Becker, D R., Rosenbaum, J. F., Hérot, C., Friedman, D., Snidman, N., Kagan, J., \& Faraone S. V. (2001) Further evidence of association between behavioral inhibition and social anxiety in children. American Journal of Psychiatry; 158, pp. 1673-1679, ISSN 0002-953X 
Caraveo, A. J., Medina-Mora, M. E., Tapia, C. R., Rascón, M. L., Gómez, M., \& Villatoro, J. (1993) Trastornos psiquiátricos en niños de la República Mexicana. Resultados de una encuesta de hogares. Psiquiatría, 9, pp.137-151, ISSN 0187-4543

Caraveo, A. J., Medina-Mora, M. E., Villatoro, J., \& Rascón M. L. (1994) La depresión en el adulto como factor de riesgo en la salud mental de los niños. Salud Mental, 17, 2, pp.56-60, ISSN 0185-3325

Caraveo A. J., Medina-Mora M. E. Villatoro J. Rascón M. L. \& Martínez V. A. (1995) El consumo de alcohol como factor de riesgo asociado a desórdenes psíquicos en los niños. Salud Mental, 18, 2, pp.18-24, ISSN 0185-3325

Caraveo-Anduaga, J. (1996) Prevalencia de trastornos psiquiátricos en la población Mexicana. Estado actual y perspectivas. Salud Mental, 19,(Suppl. 1), pp.8-13, ISSN: 0185-3325.

Caraveo, A. J., Martínez, N., \& Rivera, E. (1998) Un modelo para estudios epidemiológicos sobre la salud mental y la morbilidad psiquiátrica. Salud Mental; 21, 1, pp. 48-57, ISSN 0185-3325

Caraveo, A. J., Colmenares, B. E., \& Saldívar, H. G. (1999) Morbilidad psiquiátrica en la Ciudad de México: prevalencia y comorbilidad en la vida. Salud Mental, 22 (especial), pp. 62-67, ISSN 0185-3325

Caraveo-Anduaga, J., Nicolini, S.H., Villa, R.A., \& Wagner, E.F. (2005) Psicopatología en familiares de tres generaciones: un estudio epidemiológico en la Ciudad de México. Salud Pública De México, 47, 1, pp. 20-26, ISSN 0036-3634, ISSN 1606-7916.

Caraveo-Anduaga J. (2006). Cuestionario Breve de tamizaje y diagnóstico de problemas de salud mental en niños y adolescentes, CBTD: confiabilidad, estandarización y validez de construcción. Salud Mental, 29, 6, pp.65-72, ISSN 0185-3325

Caraveo-Anduaga J. (2007) Cuestionario Breve de tamizaje y diagnóstico de problemas de salud mental en niños y adolescentes: algoritmos para síndromes y su prevalencia en la Ciudad de México. Salud Mental, 30, 1, pp.48-55, ISSN 0185-3325

Caraveo-Anduaga, J. López J. J. L. Soriano R. A. López H. J. L. Contreras G. A. \& Reyes M. A. Eficiencia y validez concurrente del CBTD para la vigilancia de la salud mental de niños y adolescentes en un centro de atención primaria de México. (Under revision, 2011) Revista De Investigación Clínica. ISSN: 0034-8376.

Caspi, A., Moffitt, T. E., Newman, D. L., \& Silva, P. A. (1996) Behavioral observations at age 3 years predict adult psychiatric disorders. Archives of General Psychiatry, 53, pp. 1033-1039. ISSN 0003-990X

Fernández-Torres, J.E. (2005) La crisis financiera de 1994-1995 y el TLCAN a diez años [Web Page].; Accessed 2011 Apr 24. Available at: www.EUMED.NET/libros/2005/JEFT/.

Giel R., de Arango, M. V., Climent, C. E., Harding, T. W., Ibrahim, H. H. A., LadridoIgnacio, L., Srinivasa-Murthy, R., Salazar, M. C., Wig, N. N., \& Younis Y. O. A. (1981) Childhood mental disorders in primary health care: results of observations in four developing countries. Pediatrics, 68, 5, pp. 677-683, .ISSN 0003-990X

Goldsmith, H. H., Buss, K. A.., \& Lemery, K. S. (1997) Toddler and childhood temperament: Expanded content, stronger genetic evidence, new evidence for the importance of environment. Developmental Psychology, 33, pp. 891-905, ISSN 0031-4005

Hale III, W. W. Raaijmakers, Q. A. W., Muris, P., \& van Hoof, A. (2009) One factor or two parallel processes? Comorbidity and development of adolescent anxiety and 
depressive disorder symptoms. Journal of Child Psychology and Psychiatry, 50, 10, pp. 1218-1226;. ISSN: 0021-9630.

Hammen, C., Shih, J. H., \& Brennan, P. A. (2004) Intergenerational transmission of depression: Test of an interpersonal stress model in a community sample. Journal of Consulting and Clinical Psychology, 72, pp. 511-522, ISSN 0012-1649.

Hayward, C., Killen, J. D., Kraemer, H. C., \& Taylor C. B. (1998) Linking self-reported childhood behavioral inhibition to adolescent social phobia. Journal of the American Academy of Child and Adolescent Psychiatry, 37, pp. 1308-1316, ISSN 0890-8567

Kagan, J., Reznick, J. S., Clarke, C., Snidman, N., \& Garcia-Coll, C. (1984) Behavioral inhibition to the unfamiliar. Child Development, 55, pp. 2212-2225, ISSN 0009-3920.

Kendler, K., Davis, C. G., \& Kessler, R. C. (1997) The familial aggregation of common psychiatric and substance use disorders in the National Comorbidity Survey: a family history study. British Journal of Psychiatry, 170, pp. 541-548, ISSN 0007-1250

Kendler, K. S., Walters, E. E., Neale, M. C., Kessler, R. C., Heath, A. C., \& Eaves, L. J. (1995) The structure of the genetic and environmental risk factors for six major psychiatric disorders in women: Phobia, generalized anxiety disorder, panic disorder, bulimia, major depression, and alcoholism. Archives of General Psychiatry, 52, pp. 374-383, ISSN 0003-990X

Kessler, R.C., McGonagle, K. A., \& Zhao, S., Nelson, C.B., Hughes, M., Eshelman, S., Wittchen, H-U., \& Kendler, K.S. (1994) Lifetime and 12-month prevalence of DSMIII-R psychiatric disorders in the United States. Archives of General Psychiatry, 51, pp. 8-19, ISSN 0003-990X

Kessler, R. C., Nelson, C. B., McGonagle, K. A., Liu, J., Swartz, M., \& Blazer, D. G. (1996) Comorbidity of DSM-III-R major depressive disorder in the general population: results from the US National Co-morbidity Survey. British Journal of Psychiatry, 168, pp. 17-30, ISSN 0007-1250

Kessler, R.C., Aguilar-Gaxiola, S., Andrade, L., Bijl, R., Borges, G., Caraveo, A.J., De Witt, D.J., Kolody, B., Merikangas, K.R., Molnar, B.E., Vega, W.A., Walters, E.E., \& Wittchen, H-U. (2003) Cross-national comparisons of comorbidities between substance use disorders and mental disorders: Results from the International Consortium in Psychiatric Epidemiology. In: Handbook of Drug Abuse Prevention Theory, Science and Practice, Zili Sloboda \& William J. Bukoski., eds., pp. 447-472, Kluwer Academic/Plenum Publishers; ISBN 0-306-47342-9

Klein, R.G. \& Pine D.S. (2002) Anxiety disorders. In: Child and adolescent psychiatry, Michael Rutter \& Eric Taylor, (Eds.), fourth edition, pp. 486-509, Blackwell Science Ltd; ISBN 0-632-05361-5, Bath, Great Britain.

Kovacs, M. \& Devlin, B. (1998) Internalizing Disorders in Childhood. Journal of Child Psychology and Psychiatry, 39, pp.47-63, ISSN 0021-9630

Malcarne, V., Hansdottir, I., \& Merz, E. L. (2010) Vulnerability to anxiety disorders in childhood and adolescence. In: Vulnerability to psychopathology, Rick E. Ingram \& Joseph M. Price, (Eds),. pp. 291-333, The Guilford Press, ISBN 978-1-60623-347-4, New York, N.Y.

McNutt, L. N. Wu Ch. Xue X. \& Hafner J. P. (2003) Estimating the relative risk in cohort studies and clnical trials of common outcomes. American Journal of Epidemiology, 157, pp. 940-943, ISSN: 0002-9262.

Merikangas, K.R., Mehta, R. L., Molnar, B. E., Walters, E. E., Swendsen, J. D., AguilarGaxiola, S., Bijl, R., Borges, G., Caraveo-Anduaga, J., Dewit, D. J., Kolody, B., Vega, 
W. A., Wittchen, H-U., \& Kessler, R. C. (1998) Comorbidity of susbtance use disorders with mood and anxiety disorders: results of the International Consortium in Psychiatric Epidemiology. Addictive Behaviors, 23, 6, pp. 893-907; ISSN 0306-4603.

Moffitt, T. E., Caspi, A., Harrington, H., Milne, B. J., Melchior, M., Goldberg, D., \& Poulton, R. (2007) Generalized anxiety disorder and depression: childhood risk factors in a bith cohort followed to age 32. Psychological Medicine, 37, pp. 441-452, ISSN: 00332917.

Pettit, J. W., Olino, T. M., Robert, E. R., Seeley, J. R., \& Lewinsohn, P. M. (2008) Intergenerational Transmission of Internalizing Problems: Effects of Parental and Grandparental Major Depressive Disorder on Child Behavior. Journal of Clinical Child E Adolescent Psychology, 37, pp. 640-650; ISSN 1537-4416.

Rapoport, J.L. (2000) Childhood onset of "adult" psychopathology. American Psychiatric Press, Inc., ISBN 0-88048-821-2, Washington D.C.

Schwartz, C. E. Snidman, N. \& Kagan, J. (1999) Adolescent social anxiety as an outcome of inhibited temperament in childhood. Journal of the American Academy of Child and Adolescent Psychiatry, 38, pp. 1008-1015, ISSN 0890-8567.

Sheehan, D.V., Lecrubier, Y., Shytle, D., Milo, K., Hergueta, T., Colón-Soto, M., Díaz, V., \& Soto, O. (2000, c1998) Mini International Neuropsychiatric Interview for children and adolescents [M.I.N.I. KID ]. Version 1.1. Medical Outcome Systems, Inc.

Thornberry, T. P. Freeman-Gallant A. Lizotte A. J. Krohn M. D. \& Smith C. A. (2003) Linked lives: The intergenerational transmission of antisocial behavior. Journal of Abnormal Child Psychology, 31, 2, pp.171-184, ISSN: 0091-0627.

Twisk J.W.R. (2003) Applied longitudinal data analysis for epidemiology. Cambridge University Press, ISBN 0-521-52580-2, Cambridge, UK

Vega, W.A., Kolody, B., Aguilar-Gaxiola, S., Alderte, E., Catalano, R., \& Caraveo-Anduaga, J. (1998) Lifetime prevalence of DSM-III-R psychiatric disorders among urban and rural Mexican Americans in California. Archives of General Psychiatry, 55, pp. 771778, ISSN 0003-990X

Warner, V., Wickramaratne, P., \& Weissman, M. M. (2008) The role of fear and anxiety in the familial risk for major depression: a three-generation study. Psychological Medicine, 38, pp.1543-1556, ISSN 0033-2917.

Weissman, M.M., Warner, V., Wickramaratne, P., Moreau, D., \& Olfson, M. (2000) Offspring at risk: Early-onset major depression and anxiety disorders over a decade. In: Childhood onset of "adult" psychopathology, Judith L..Rapoport (ed), pp. 245-258, American Psychiatric Press, Inc., ISBN 0-88048-821-2; Washington D.C.

Weissman, M. M., Wickramaratne, P., Nomura, Y., Warner, D., Verdeli, H., Pilowsky, D. J., Grillon C., \& Bruder, G. (2005) Families at high and low risk for depression: A three generation study. Archives of General Psychiatry, 62, pp.29-36, ISSN 0003-990X

World Health Oragnization. (1993) The ICD-10 Classification of Mental and Behavioural Disorders: Diagnostic criteria for research. MEDITOR, ISBN 84-87548-13-X, Madrid, España. 


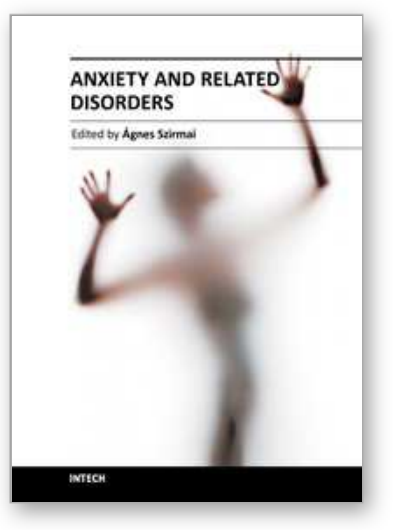

\author{
Anxiety and Related Disorders \\ Edited by Dr. Ãgnes Szirmai
}

ISBN 978-953-307-254-8

Hard cover, 292 pages

Publisher InTech

Published online 29, August, 2011

Published in print edition August, 2011

Anxiety disorders are one of the most common psychiatric disorders worldwide and many aspects of anxiety can be observed. Anxious patients often consult primary care physicians for their treatment, but in most cases they do not accept the diagnosis of anxiety disorder. Anxiety is a symptom that could be seen in many organic disorders and can accompany almost any psychiatric disorder. Anxiety disorders are frequent and are associated with significant distress and dysfunction. Stigmatization is an important factor in insufficient diagnosis. The problems of anxiety cover all fields of life. This book intends to describe the epidemiological aspects and the main co-morbidities and consecutive diseases of the anxiety disorders.

\title{
How to reference
}

In order to correctly reference this scholarly work, feel free to copy and paste the following:

Jorge Javier Caraveo-Anduaga (2011). Intergeneration Familial Risk and Psychosocial Correlates for Anxiety Syndromes in Children and Adolescents in a Developing Country, Anxiety and Related Disorders, Dr. Ãgnes Szirmai (Ed.), ISBN: 978-953-307-254-8, InTech, Available from: http://www.intechopen.com/books/anxietyand-related-disorders/intergeneration-familial-risk-and-psychosocial-correlates-for-anxiety-syndromes-inchildren-and-adol

\section{INTECH}

open science | open minds

\section{InTech Europe}

University Campus STeP Ri

Slavka Krautzeka 83/A

51000 Rijeka, Croatia

Phone: +385 (51) 770447

Fax: +385 (51) 686166

www.intechopen.com

\section{InTech China}

Unit 405, Office Block, Hotel Equatorial Shanghai

No.65, Yan An Road (West), Shanghai, 200040, China

中国上海市延安西路65号上海国际贵都大饭店办公楼 405 单元

Phone: +86-21-62489820

Fax: +86-21-62489821 
(C) 2011 The Author(s). Licensee IntechOpen. This chapter is distributed under the terms of the Creative Commons Attribution-NonCommercialShareAlike-3.0 License, which permits use, distribution and reproduction for non-commercial purposes, provided the original is properly cited and derivative works building on this content are distributed under the same license. 